\title{
Constructive Empiricism and Deflationary Truth*
}

\author{
Jamin Asay ${ }^{\dagger}$
}

Constructive empiricists claim to offer a reconstruction of the aim and practice of
science without adopting all the metaphysical commitments of scientific realism. De-
flationists about truth boast of the ability to offer a full account of the nature of truth
without adopting the metaphysical commitments accompanying substantive accounts.
Though the two views would form an attractive package, I argue that the pairing is
not possible: constructive empiricism requires a substantive account of truth. Iarticulate
what sort of account of truth and empirical adequacy the constructive empiricist must
offer and then show why deflationists cannot uphold such an account.

1. Introduction. Constructive empiricists, those who espouse the brand of scientific antirealism authored and championed by Bas van Fraassen (1980), claim to offer an adequate reconstruction of the aim and practice of scientific inquiry, all without adopting some of the more substantive ontological and theoretical commitments of scientific realism. ${ }^{1}$ The goal of scientific practice, according to the constructive empiricist, is not to produce true theories but rather to produce empirically adequate theories. A theory is empirically adequate just in case everything it says about the observable features of observable objects is true. Hence, van Fraassen uses truth to define both scientific realism and constructive empiricism. Realists think that science aims for the truth about the observable and

*Received August 2009; revised September 2009.

$\dagger$ To contact the author, please write to: Department of Philosophy, University of North Carolina at Chapel Hill, Campus Box 3125, Chapel Hill, NC 27599-3125; e-mail: asay@email.unc.edu.

\$My thanks go out to Marc Lange, Keith Simmons, and especially John Roberts, whose contributions and suggestions significantly helped shape the final form of this essay. Thanks also go to the participants of the 2006 Carolina Philosophy Retreat at Cranberry Lake, NY, who heard and offered helpful feedback on a very preliminary sketch of the ideas presented here.

1. See Sellars 1963 and Putnam 1975 for some classic defenses of scientific realism. More recently, scientific realism has been defended by Psillos (1999) and Kitcher (2001).

Philosophy of Science, 76 (October 2009) pp. 423-443. 0031-8248/2009/7604-0002\$10.00

Copyright 2009 by the Philosophy of Science Association. All rights reserved. 
the unobservable; constructive empiricists argue that science settles simply for the truth about the observable.

Theories of truth come in a variety of flavors, some more metaphysically stark than others. On the one hand, there are theories that analyze truth in terms of some further property, such as correspondence with the facts, coherence, or practical utility. I refer to such theories as being substantive, in that they admit that the notion of truth is deserving of substantial philosophical analysis. On the other hand, there are deflationary theories of truth that deny that all truths share a common nature. It is true that snow is white and true that there are penguins, but those two truths do not share any common feature in virtue of which they are true. Deflationists do not posit any of the entities found in more substantive accounts, such as a correspondence relation or realm of facts, in order to understand the nature of truth. Constructive empiricism and deflationism about truth, then, seem to form a natural pair; both are motivated by the traditional empiricist inclination to make do with as little metaphysics as possible. ${ }^{2}$ My contention is that the pairing is not possible - constructive empiricism requires a more substantive account of truth than can be offered by the deflationist.

The essay proceeds, in Section 2, by canvassing briefly deflationary accounts of truth. In Section 3, I explore one attempt at merging constructive empiricism with deflationism, albeit one that does not employ the semantic account of scientific theories. Section 4 incorporates the semantic theory, and I show (with help from the Game of Life) what kind of account of truth and empirical adequacy the deflationist constructive empiricist may offer. I argue in Section 5 that such an account is untenable. I conclude that constructive empiricists must take on some commitments that they normally would rather avoid, while deflationists are unable to understand the aim of science in the way that constructive empiricists suggest.

2. Deflationary Truth. For our purposes, we may divide theories of truth into substantive and deflationary accounts. Substantive accounts (including the traditional correspondence, coherence, epistemic, and pragmatic theories) hold that truths share some common feature in virtue of which they are true. Substantivists about truth think that the project of the theory

2. Compare Teller 2001: "van Fraassen, with his empiricist's distaste for metaphysical commitments, is going to be leery of espousing anything like the correspondence theory of truth as a metaphysical view. . . . He will want to make full use of our robustly effective practices of talk about truth without further analysis or metaphysical commitments" (143). 
of truth is to offer a philosophical analysis of what that feature is. ${ }^{3}$ Correspondence theorists, for example, hold that truth can be analyzed in terms of truth bearers and facts standing in the correspondence relation. In his earlier work, van Fraassen seems to adopt a correspondence theory of truth: "I would still identify truth of a theory with the condition that there is an exact correspondence between reality and one of its models" (1980, 197). ${ }^{4}$ More recently, van Fraassen has cried "mea culpa!" on such statements and distanced himself from correspondence theories (2006, 153; see also his 2008, 247-249). Given van Fraassen's current penchant for deflationism, our question of whether constructive empiricism requires a substantive theory of truth or whether it can make do with only a deflationary account is particularly pertinent.

Deflationists about truth reject the very enterprise of offering an analysis of truth, at least in the sense employed by traditional truth theorists. Deflationists hold that truths do not share some common property that accounts for their truth (Quine 1970; Horwich 1990; Field 1994). Each truth has its own individual subject matter in which its truth consists. It is true that snow is white because snow is white, not because 'Snow is white' stands in the correspondence relation to some fact. In order to evaluate whether deflationism can be conjoined consistently with constructive empiricism, we must highlight two features common to most brands of deflationary truth. Following Bar-On and Simmons (2007), we can identify two theses common to most accounts of deflationism. First is linguistic deflationism, the claim that the truth predicate primarily is a logical device for disquotation..$^{5}$ Appending the truth predicate to a sentence adds no cognitive content to the sentence. Field, for example, argues that the sentences 'Snow is white' and "Snow is white" is true' are $\operatorname{cog}$ nitively equivalent: they mean the exact same thing to the speaker who utters them (1994, 251). Accordingly, any sentence involving the truth predicate can be replaced, without change in truth value or meaning, by another sentence not employing the predicate. To take a canonical kind

3. I also take primitivism - the view endorsed by Frege ([1918-19] 1956) and Davidson (1996) that truth is a conceptual primitive that resists analysis - to be a species of substantivism.

4. See also van Fraassen 1980, 90; 1987, 122; and 1991, 242. Ellis (1985, 49), Bub and MacCallum (1988, 398), Jennings (1989, 236), and Psillos (1999, 179) similarly detect a correspondence theory of truth in van Fraassen. Fine detects more ambiguity in van Fraassen's attitude toward truth but provides textual evidence only of van Fraassen's substantivism (1984, note 5, and 1986, 157). See Rosenhagen 2006 for discussion.

5. Note that for a deflationist like Horwich, truth plays a denominalizing rather than a disquotational role. Horwich's account adopts propositions, so the axioms of his account (such as 'The proposition that snow is white is true just in case snow is white') involve no disquotation (unlike in sentential accounts like Quine's and Field's). 
of example, consider the sentence 'Something Kant said is true'. The deflationist offers a translation of that sentence without using the truth predicate. The deflationist might offer a quantified statement: 'There exists some $p$ such that Kant said that $p$ and $p{ }^{6}{ }^{6}$ Or the deflationist might offer an infinitely long statement: 'Kant said that snow is white, and snow is white, or Kant said that grass is green, and grass is green, or . . . The deflationist claims that any use of the truth predicate similarly can be circumvented. Nevertheless, the truth predicate has an important expressive role to play in our language, in that it allows us to make such infinitely long statements in a manageable, finite manner.

Although all deflationists accept linguistic deflationism, some substantivists do as well (e.g., Frege [1918-19] 1956). Thus, deflationists are also marked by their adoption of a second thesis, conceptual deflationism. Conceptual deflationism is the view that truth does not play an indispensable role in the philosophical analysis or explanation of other concepts that goes beyond its function as a device for disquotation or denominalization. For example, Michael Williams writes that "the function of truth talk is wholly expressive, thus never explanatory. . . . What makes deflationary views deflationary is their insistence that the importance of truth talk is exhausted by its expressive function" (1999, 547). Were an analysis to regard truth either as a conceptual primitive (as in Davidson 1996), or as an essential component of the analysis beyond its disquotational or denominalizing role, the analyst would be relying on truth in a robust, nondeflationary manner. Consider, for example, Frege's analysis of assertion. Frege embraces linguistic deflationism: "It seems, then, that nothing is added to the thought by my ascribing to it the property of truth" ([1918-19] 1956, 293). Yet he thinks that what separates assertions (my sincere expression of my belief that snow is white) from nonassertoric speech acts (an actor's saying that snow is white during a performance) is that assertions put forward a thought as being true. Substantivists about truth can analyze the concept of assertion by appealing to the notion of truth - they can allow that there is a rich conceptual connection between truth and assertion. Deflationists, however, must deny that there are any such connections. Both the linguistic and conceptual deflationary theses can be attributed to most deflationists. No substantivist would subscribe to conceptual deflationism, so the two theses in combination adequately define a standard deflationist position. ${ }^{7}$ The task now is to determine whether constructive empiricism can sustain such deflationism.

6. The quantification here is usually understood substitutionally.

7. Bar-On and Simmons (2007) also identify a third deflationary thesis, metaphysical deflationism, which states that truth is not a genuine property. But Horwich admits that truth is a perfectly good property and thus seems to reject metaphysical defla- 
3. Constructive Empiricism and Deflationary Truth: A First Pass. In order for constructive empiricism and deflationism about truth to form a consistent pair, the deflationist constructive empiricist must be able to offer a statement of his view that does not rely conceptually on truth in any way that goes beyond its disquotational or denominalizing role. Constructive empiricism is the view that the aim of scientific inquiry is to produce empirically adequate theories, where a theory is empirically adequate just in case everything involving the observable features of observable objects to which the theory is committed is true (van Fraassen 1980, 12). Since that position makes reference to the concept of truth, we must investigate whether it can be disquoted or denominalized away in typical deflationist fashion. Now, what the account needs to look like depends on whether the syntactic or semantic view of theories is adopted. According to the syntactic view, scientific theories are identified as sets of sentences. On the semantic account, a scientific theory is identified as a class of models, each offering a putative representation of the world. Van Fraassen argues against the syntactic theory $(1980,53-56)$ and has been a leading proponent of the semantic account. I shall assume alongside van Fraassen that those arguments are decisive (see also Suppe 1989) and that constructive empiricists should adopt the semantic account of theories. Nevertheless, it will be instructive to look at what truth and empirical adequacy would look like for the deflationist on the syntactic view, were we indeed able to think of theories as mere sets of sentences.

Our goal is to offer an analysis of the truth and empirical adequacy of a scientific theory in such a way that it relies on truth only as a device for disquotation or denominalization. Above, we saw that deflationists divide as to whether they rely on quantified statements ('There is some $p$ such that Kant said that $p$ and $p$ ') or infinitary statements ('Kant said that snow is white, and snow is white, or . . .'). For ease of exposition, I shall assume the latter approach. ${ }^{8}$ As a first pass, then, consider the following deflationary accounts of truth and empirical adequacy:

$\mathbf{T}_{1}$. Scientific theory $T$ is true if and only if: $T$ entails 'There are electrons' if and only if there are electrons, and $T$ entails 'Snow is white' if and only if snow is white, and . . .

$\mathbf{E A}_{1}$. Scientific theory $T$ is empirically adequate if and only if: if 'There are electrons' expresses only observable (putative) facts, then $T$ entails 'There are electrons' if and only if there are electrons, and if 'Snow

tionism $(1990,38)$. Hence, I am not considering metaphysical deflationism to be necessary for the kind of deflationism I am engaging.

8. There is a rich literature debating the relative merits of the two approaches. See Horwich 1990, David 1994, Hill 2002, and Künne 2003 for a representative sample. 
is white' expresses only observable (putative) facts, then $T$ entails 'Snow is white' if and only if snow is white, and . . '

$\mathbf{T}_{1}$ is straightforward and is what one would expect from a deflationist. The biconditionals that form each of its conjuncts ensure that $T$ is comprehensive. When speaking of theories, van Fraassen routinely observes that they must speak to all the phenomena in order to be empirically adequate, and to the entire world in order to be true (e.g., 1980, 64, and 1989, 226). EA is more worrisome, as it singles out those sentences that "express only observable (putative) facts." A complete defense of $\mathbf{E A}_{1}$ should include an explanation of what it is for a sentence to express only observable (putative) facts. Some logical positivists took recourse here to a pure observation language. But since such an appeal is unlikely nowadays to provide a satisfying method for distinguishing a theory's empirical and unempirical consequences, the advocate of the syntactic view must offer some other syntactic account of when sentences express only observable (putative) facts. The legacy of the syntactic account suggests that no such project will be successful. I have no argument for the conclusion that no adequate defense of the syntactic view is forthcoming. Instead, I shall continue to assume with van Fraassen that the semantic view of theories is preferable to the syntactic view and that constructive empiricists ought not to take on the burden of defending the latter.

Now, the reason that we cannot accept $\mathbf{T}_{1}$ and $\mathbf{E} \mathbf{A}_{1}$ is not that they rely on truth in a nondeflationary matter. $\mathbf{T}_{\mathbf{1}}$ is acceptable to the deflationist, and $\mathbf{E A}_{1}$ is as well, provided that observability also can be analyzed without in turn relying on truth in a nondeflationary way. ${ }^{10}$ This essay is not the place to delve into van Fraassen's understanding of observability, but it is worth pointing out that it is at least plausible that he will not need to appeal to truth in order to offer an analysis of observability. Objects are observable in virtue of features such as their size, color, and odor. It is not obvious how truth might make its way into that picture. ${ }^{11}$ So the problem for $\mathbf{T}_{1}$ and $\mathbf{E} \mathbf{A}_{1}$ is that they rely on the inadequate syntactic account of scientific theories, an account which the constructive empiricist

9. I make reference to "putative" facts so as to disallow theories that include false implications about the observable from being true. For example, consider an otherwise true theory that also included the sentence 'Snow is green'. It is false that the sentence expresses only observable facts (for it expresses something false), but it is true that it expresses only observable (putative) facts. Were it not to mention putative facts, EA would hold that the 'Snow is green' theory is empirically adequate. Note that I am employing 'fact' in a neutral way. By 'fact' I simply mean 'true bearer of truth'.

10. My thanks to an anonymous referee for calling my attention to this point.

11. See Muller 2005 for a detailed examination into what kind of account of observability a constructive empiricist may hold. 
does not accept. Accordingly, we must now develop an account of the truth and empirical adequacy of scientific theories that utilizes the semantic account instead. For the constructive empiricist, a theory is true just in case one of its models is isomorphic to the actual world and empirically adequate just in case the empirical substructures of one of its models are isomorphic to the observable world (van Fraassen 1989, 226 227). Our task now is to determine whether the deflationist can make sense of such notions.

4. The Game of Life. We can understand better the semantic (or modeltheoretic) account of scientific theories by examining a very simple example that utilizes John Horton Conway's game Life (see Gardner 1970). Let me stress just how much simplicity is involved. No actual scientific theory is anywhere near as simple as the Life theories I shall be considering. Still, I find the Life example to be instructive precisely because of its simplicity. Since the problem for the deflationist constructive empiricist is present even in our simple example, it is unlikely to disappear in the context of a more complicated theory.

Life provides a simple deterministic system such that its future states systematically can be deduced from its earlier states. A Life world consists of a two-dimensional grid of cells. At any given time, each cell is in one of two possible states (ON or OFF). Any noninitial configuration of the grid can be deduced from the previous configuration and the "laws" that describe the transformations of the grid over time. ${ }^{12}$ Whether a cell is oN or OFF at a particular time depends entirely on whether its neighboring cells (including diagonals) were ON or OFF during the previous time. Life operates according to three simple rules:

$\mathbf{A}_{1}$. If at time $t_{n}$ any cell has exactly two neighboring ON cells, then that cell remains in the same state at $t_{n+1}$.

$\mathbf{A}_{2}$. If at time $t_{n}$ any cell has exactly three neighboring ON cells, then that cell is ON at $t_{n+1}$.

$\mathbf{A}_{3}$. If at time $t_{n}$ a cell is under any other condition, then that cell is OFF at $t_{n+1}$.

Figure 1 shows a simple three-stage Life transformation on a nine-celled grid (gray squares denote the ON position, white squares the OFF position): Were this pattern to be continued, all subsequent configurations (at $t_{3}$ and beyond) would be identical to the entirely OFF configuration at $t_{2}$ (for a "dead" grid cannot be "resuscitated").

12. The "laws" here are not assumed to be anything that might be distasteful to a constructive empiricist (or van Fraassen himself-see his 1989). 


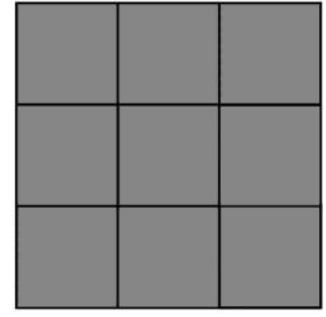

$\mathrm{t}_{0}$

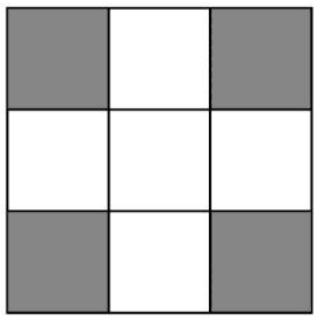

$t_{1}$

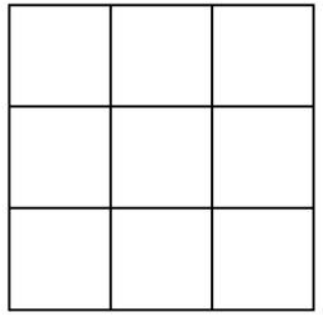

$t_{2}$

Figure 1.

We can use the Game of Life to give an example of what a modelbased scientific theory looks like. Imagine a universe that consisted of nothing more than what we find in the Life universe, a universe that could be described exhaustively by specifying at every time whether each of its cells was in the ON or OFF state. Suppose we wanted to construct a scientific theory that modeled such a universe. To do so, we would need to define the mathematical structures that will serve as representations of the various components of the universe. The first thing to be defined would be a set of nine ordered pairs, each representing a cell on the grid: $\{\langle 1,1\rangle,\langle 1,2\rangle, \ldots,\langle 3,3\rangle\}$. We would also need to define the neighbor relation, which specifies the cells that are neighbors to each other. Also included would be the axioms $\mathbf{A}_{1}, \mathbf{A}_{2}$, and $\mathbf{A}_{3}$, which serve as the laws, or just fundamental regularities, of the theory. Given that minimal structure and apparatus, the theory can be defined in terms of a set of models that are consistent with the given structure. Distinguishing each model of the Life theory would be a function that assigned to each ordered pair an initial value from the set $\{0,1\}$, representing the features OFF and oN, respectively. The individual moments of time in the Life universe are assigned natural numbers. Since our universe has nine cells, there are $2^{9}$ or 512 unique initial configurations. ${ }^{13}$ Because the Life universe operates deterministically, each initial configuration leads to one particular future. Now suppose that the history of the universe began as in the example above, with each cell initially in the ON position. Because the universe is a Life universe, it behaves according to the axioms of the theory. Thus, the Life theory offers an accurate representation of the universe, for one of its

13. Note that one could define the Life theory without building into the structure that there are nine cells. One might instead offer a more general version of the theory that left it open to the individual models to specify how many cells were in the universe. Such a theory would have infinitely many models, 512 of which are the ones included in the narrower theory I am offering. 
models (namely, the one whose initializing function assigns ' 1 ' to each ordered pair) correctly describes the actual state of each cell at every time of its history.

To summarize, then, our Life theory $L$ of the nine-celled universe is to be identified with a set of 512 models. Each model of $L$ is in turn identified with a single function. That function takes two inputs, ordered pairs defined over $\{1,2,3\}$ and members of the set of natural numbers, and maps them to a member from the set $\{0,1\}$. What makes each of the 512 models models of $L$ is the fact that it is consistent with the above axioms of the Life game. Models that are not consistent with those axioms are not models of $L$. For example, the function that assigns ' 1 ' to each ordered pair at $t_{0}$ and yet assigns ' 1 ' also to each ordered pair at $t_{1}$ is not a model of $L$ but perhaps of some other non-Life theory. ${ }^{14}$

Another feature of the Game of Life is that it easily can be modified to make sense of the distinction between observables and unobservables, making it an especially helpful example for the constructive empiricist. One way that one might introduce the distinction is simply by demarcating some of the Life matrix as being unobservable. For example, suppose that the top row of the Life world depicted above is unobservable. Statements involving the features of the top row would not count as expressing observable phenomena, whereas statements involving only the lower two rows would. Constructive empiricists can find that picture of the unobservable appealing, for it suggests that the unobservable and observable are "metaphysically continuous": the unobservable regions of the universe are just as real as the observable regions and have the same features. The regions differ only in their epistemic accessibility (for whatever reason that might be). Further, the empirical substructures of a model easily could be defined. The empirical substructures in the case of a Life world would be identical to partial functions that map only the observable regions of the cell matrix paired with times to the relevant values.

The Game of Life is helpful in elucidating what constitutes a model of a scientific theory. But there is more to the semantic view of theories than just models. The view is semantic because it stresses that scientific theories always involve an intended interpretation. ${ }^{15}$ For the Life world depicted

14. Van Fraassen's own presentation of the model-theoretic view of theories differs slightly from my own, given his choice of examples. (He also presents his view using the technical vocabulary of state spaces, elementary statements, and satisfaction functions.) The picture provided using the Life game, I think, better helps elucidate the potentially confounding notion of a model. For full exposition of van Fraassen's description of models, see van Fraassen 1970, 328-329, and 1972, 311-312; Suppe 1989; and Thompson 1989, 77-81.

15. See van Fraassen 1997 for an excellent discussion of just how important interpretations are. 
above, $L$ provides an accurate picture of the universe - one of its models is perfectly isomorphic to every state of that universe's history. But we must understand $L$ as the conjunction of its models and an interpretation. The theory's interpretation plays the role of pairing the mathematical structure of the theory's models with the real features of the world. To define the intended interpretation $I$ of $L$, we need to define three one-one functions. The first $\left(i_{1}\right)$ takes cells to ordered pairs. In the Life world, the cells are the real objects. Hence $I$ includes a function taking cells, each named with a letter from $\{A, B, \ldots, I\}$, to ordered pairs defined over $\{1,2,3\}$. Next there is a function $\left(i_{2}\right)$ that takes the real features ofF and ON to members of the set $\{0,1\}$, respectively. Finally, a third function $\left(i_{3}\right)$ maps actual times with the set of natural numbers: $t_{0}$ with $0, t_{1}$ with 1 , and so on. I now provides a semantics for $L$. $L$, again, includes 512 models, which constitute the set of functions $\left\{M_{1}, M_{2}, \ldots, M_{512}\right\}$. Each model $M_{n}$ is a function that takes two inputs (an ordered pair and a natural number) to the set $\{0,1\}$. Let $\Phi$ be a variable ranging over the set of cells, $\varphi$ a variable ranging over the set of features, and $t$ a variable ranging over the set of times. We can now define the notion of truth-in-a-Life model: For any Life sentence of the form ' $\Phi$ is $\varphi$ at $t$ ',

' $\Phi$ is $\varphi$ at $t$ ' is true-in- $M_{n}$ if and only if $M_{n}\left(i_{1}(\Phi), i_{3}(t)\right)=i_{2}(\varphi)$.

Hence, the ordinary statements that can be used to describe the Life universe (' $A$ is ON at $t_{0}^{\prime}$, ' $E$ is OFF at $t_{2}$ ') can be evaluated from the perspective of each model of the theory. Such statements often will be true in some models but not in others. For example, consider the sentence ' $A$ is ON at $t_{0}$ '. From the perspective of $M_{1}$, the model where every cell begins in the OFF position, the sentence is false (not true-in- $M_{1}$ ). $M_{1}$ says that the first cell in the grid is OFF at the initial time: $M_{1}(\langle 1,1\rangle, 0)=0$. From the perspective of $M_{512}$, the model where every cell begins in the ON position, the sentence is true (true-in- $\left.M_{512}\right): M_{512}(\langle 1,1\rangle, 0)=1$.

We have now defined the notion of truth-in-a-Life model, which will be useful in offering the accounts of truth and empirical adequacy that the deflationist constructive empiricist can offer. A true theory, again, is one that has a model that is isomorphic to the actual world. An empirically adequate theory is one that has a model whose empirical substructures are isomorphic to all phenomena. We can now analyze truth and empirical adequacy in terms of truth-in-a-model, as defined above. We shall also need to employ the derivative notion of truth-in-an-empirical substructure (true-in- $E_{n}$ ). That notion could be defined similarly, for the empirical substructures of a model are just a partial function of the model's function, a function whose domain is a subset of the model's domain. (In our case, the partial function operates over just the ordered pairs representing the 
two lower rows of cells.) The following accounts naturally suggest themselves:

$\mathbf{T}_{2}$. Scientific theory $T$ is true if and only if there is a model $M_{n}$ of $T$ such that 'There are electrons' is true-in- $M_{n}$ if and only if there are electrons, and 'Snow is white' is true-in- $M_{n}$ if and only if snow is white, and ...

$\mathbf{E A}_{2}$. Scientific theory $T$ is empirically adequate if and only if there is a model $M_{n}$ of $T$ and an empirical substructure $E_{n}$ of $M_{n}$ such that if 'There are electrons' is decided by $E_{n}$, then 'There are electrons' is true-in- $E_{n}$ if and only if there are electrons, and if 'Snow is white' is decided by $E_{n}$, then 'Snow is white' is true-in- $E_{n}$ if and only if snow is white, and . .

Note that the biconditionals appearing in the definition of empirical adequacy are nested as the consequents of conditional statements whose antecedents make use of the notion of decidability. The empirical substructures of models fall silent on matters concerning the unobservable. For example, if the sentence ' $A$ is ON at $t_{0}$ ' expresses an unobservable (putative) fact, then it will fail to be true in the empirical substructures of the models of $L$ (even if it is true in the corresponding models), since the functions used to define the notion of truth-in- $E_{n}$ are undefined with respect to cell $A$. Hence, ' $A$ is ON at $t_{0}$ ' fails to be decided by $E_{1}, E_{2}$, and all the others. Only statements concerning exclusively the observable will be decided by empirical substructures; $\mathbf{E A}_{2}$ is thus defined so as to make statements involving the unobservable irrelevant to the evaluation of a theory's empirical adequacy.

5. Why Constructive Empiricists Cannot Be Deflationists. We have now seen what kind of accounts of truth and empirical adequacy the constructive empiricist has on offer if he hopes to demonstrate that his notions are consistent with both the semantic account of scientific theories and the deflationary theory of truth. Our task now is to explore why even those accounts are inadequate and cannot be sustained by deflationists. I shall raise four separate objections, in ascending order of importance, which are all related to the appeal to truth-in-a-model. First, the deflationist constructive empiricist is at pains to explain what truth-in-a-model is for a real scientific theory. Second, the deflationist constructive empiricist cannot say, in general, in what truth-in-a-model consists. As a result, his account reduces truth to indefinitely many further semantic concepts. Third, the deflationist constructive empiricist cannot explain why truthin-a-model, rather than some other notion, is central to understanding the aim of science. Finally, and most decisively, $\mathbf{T}_{\mathbf{2}}$ and $\mathbf{E} \mathbf{A}_{\mathbf{2}}$ are not even 
disquotational accounts of truth and empirical adequacy, despite appearances to the contrary.

The first problem for the deflationist constructive empiricist deals with specifying what truth-in-a-model is for genuine scientific theories. Above we saw what a truth-in-a-Life model is. Equipped with that understanding, we can fully specify what it is for a Life theory to be true. What, however, of other theories? What is it for the theory of Newtonian mechanics or the theory of evolution by natural selection to be true? Presumably, any adequately developed scientific theory includes an adequately developed interpretation. Theories are tested against the world, and thus interpretations are needed in order to connect the theory's mathematical structures with the phenomena observed in the world. Giving an account of what those interpretations are is certainly an arduous task. For the simple and contrived Life theory, formulating the interpretation is fairly uncomplicated. Real scientific theories involve far more intricate mathematical structure. In the actual world, it is true that snow is white. But what is it for 'Snow is white' to be true in the models of general relativity, or quantum mechanics? For the deflationist constructive empiricist, the heart of the problem is this: if we lack an understanding of the interpretation of a scientific theory, and thus lack an understanding of what truth-in-amodel is for that theory, then our understanding of what it is for that theory to be true or empirically adequate is also incomplete. As a result, the deflationist cannot say what it is for some genuine scientific theory to be true or empirically adequate; furthermore, to the extent that his account is incomplete, he cannot be confident that the notions of truth and empirical adequacy to which he appeals are even open to the deflationist (for an inconsistency may be lurking in the details).

There is a far greater difficulty, however, for the above accounts of truth and empirical adequacy. The crux of the problem for the deflationist lies in the fact that the definientia they offer for truth and empirical adequacy involve the semantic notion of truth-in-a-model, which cannot be understood as a general, intertheoretical notion. Instead, the notion must always be understood relative to the theory whose truth or empirical adequacy is at stake. Because there is no general notion of truth-in-a-model, the deflationist is left without a way of articulating, in general, in what the truth or empirical adequacy of a theory consists. Recall that for the typical deflationist, the truth predicate exists solely for its disquotational or denominalizing functions. The truth predicate allows us to say things like 'Something Kant said is true', things that would be impossible to say without the truth predicate on account of their infinite length. Nevertheless, the deflationist can show what those infinite statements look like and note how they do not presuppose any further semantic notions. The truth predicate, for the deflationist, is conceptually isolated, unsupported by 
further semantic notions. It can be done away with. That kind of deflationism about truth is simply not possible for the deflationist constructive empiricist who advocates $\mathbf{T}_{\mathbf{2}}$ and $\mathbf{E} \mathbf{A}_{2}$. The deflationist, of course, is always free to make use of the truth predicate. He can say, for example, that the aim of science is to produce theories that are true to the phenomena. But to demonstrate that truth, in his understanding of the aim of science, is functioning only as a device for disquotation or denominalization, the deflationist must be able to offer an account devoid of any further mention of semantic concepts (just as the deflationist account of 'Something Kant said is true' makes no use of any such concept). What the deflationist constructive empiricist appears to have to do, however, is make reference not to just one further semantic concept but to indefinitely many semantic concepts - one for each model of every possible scientific theory. Consequently, the deflationist constructive empiricist has not yet offered an account of his position that is acceptable on deflationary grounds. His analysis of truth (and empirical adequacy also) must rely on indefinitely many semantic concepts (most of which are concepts for which he has no complete understanding).

Perhaps the above two objections are not fully convincing. The deflationist might offer the following reply:

When it comes to the interpretations of our best current scientific theories, we of course do not have a fully worked out account, but neither does anyone else. It is unreasonable to charge deflationists with a special burden due to the incomplete interpretations. Further, our account does indeed reduce truth to the notion of truth-in-amodel. We admit that there is no generalized account of the truth of scientific theories - but that is exactly what we always have been stressing: truth is a thin concept, one that does not require a general account. There is nothing, in fact, that true theories have in common. Further, although we have reduced truth to truth-in-a-model, there is nothing metaphysically substantive about truth-in-a-model. In fact, we have seen an example (the Life theory) that defines explicitly what truth-in-a-model is. Truth-in-a-model is merely a technical mathematical notion, defined by stipulation, and thus devoid of metaphysical substance. To understand it we do not need to bring in metaphysical posits like a correspondence relation or realm of facts. Finally, as $\mathbf{T}_{2}$ and $\mathbf{E} \mathbf{A}_{2}$ clearly show, truth-in-a-model still functions as a device for disquotation. Hence, they are after all acceptable to the deflationist.

The deflationist's reply, however, is lacking. Let us consider in turn each of his rebuttals. The deflationist is correct to point out that no one, even those who adopt the most robust account of truth available, has an ad- 
equate grasp of what the interpretations are for our best scientific theories. Still, it seems that deflationists carry an extra burden as a result of the missing interpretations. If the deflationist constructive empiricist wishes to appeal to the concept of truth when articulating his position, he must be prepared to demonstrate that the notion presupposes nothing more substantive than a deflationist can allow. Since his account of truth rests on numerous other concepts (all varieties of truth-in-a-model), the deflationist is at pains to show that those concepts are themselves acceptable to the deflationist. To the extent that the deflationist constructive empiricist leaves unanalyzed the constituents of his notion of truth, he cannot claim justifiably that his account is genuinely deflationary.

Further, while it is true that the deflationist usually (and justifiably) claims not to be obligated to offering a general account of truth, the deflationist constructive empiricist is so obliged. Constructive empiricists employ the concept of truth for a use that goes beyond truth's typical disquotational and denominalizing role, for they use it in formulating both their and their opponent's positions. According to the constructive empiricist, the aim of science is to construct empirically adequate theories, regardless of what kind of theory is being considered. The deflationist constructive empiricist's statement about his own position appeals to the notion of empirical adequacy simpliciter, yet he has no recourse to a similar, general notion of truth-in-an-empirical substructure for his deflationist reduction. If the central thesis of constructive empiricism is to have any content at all, it must be anchored by some general concept of truthin-a-model.

As we have seen, the deflationist constructive empiricist appeals to indefinitely many individual notions of truth-in-a-model. It is a fair question, then, to ask what those notions have in common and why they are all acceptable on metaphysically austere deflationary grounds. We have now arrived at the third objection. Given the formalized definition of truth-in-a-Life model that I offered above, it may appear that the notion is metaphysically innocuous. The notion was defined mathematically, with no reference to a suspicious correspondence relation or anything else typically distasteful to the deflationist. Notice, though, that we could have defined several other notions as well. Let us define the notion of waarheidin-a-model. ${ }^{16}$ Suppose we add another one-one function, $i_{4}$, to our interpretation $I$ of the Life theory. The new function, like $i_{2}$, assigns to features members of $\{0,1\}$, but makes the opposite assignments. Thus, $i_{4}(\mathrm{ON})=$ 0 and $i_{4}(\mathrm{OFF})=1$. Now we can define the notion of ' $w a a r$-in- $M_{n}$ ': for any Life sentence of the form ' $\Phi$ is $\varphi$ at $t$ ',

16. 'Waarheid' is Dutch for 'truth'. 
' $\Phi$ is $\varphi$ at $t$ ' is waar-in- $M_{n}$ if and only if $M_{n}\left(i_{1}(\Phi), i_{3}(t)\right)=i_{4}(\varphi)$.

As the two semantic notions are defined, no basic Life sentence can be both true-in- $M_{n}$ and waar-in- $M_{n}$ for the same $n$. (Indeed, 'waar' seems to be synonymous with 'false'!) Now, clearly the deflationist must opt for using true-in- $M_{n}$ rather than waar-in- $M_{n}$ in his definition of truth for a Life theory. But what rationale can the deflationist offer to explain why the former concept belongs in his notion of truth rather than the latter? Further, even supposing that we define a true theory as in $\mathbf{T}_{2}$, and a waar theory analogously (by substituting 'waar' everywhere 'true' appears), what explanation could we offer for why the realist thinks that the aim of science is to produce true theories, rather than waar theories? And why should the constructive empiricist think that the aim of science is to produce theories that are true to the phenomena, rather than waar to the phenomena?

The appropriate response to those questions, it seems to me, involves some reasoning like the following: of all the semantic notions of which we can conceive, one in particular stands out. For our Life theory, defining what it is for a sentence to be true-in- $M_{n}$ is essential for understanding what it is for a Life theory to be true. Other notions, like waar-in- $M_{n}$ and indefinitely many others that we could define at our leisure, simply do not suffice. Truth-in- $M_{n}$ is the privileged semantic notion and not because of its arbitrarily chosen name (I could very well have swapped 'true' and 'waar' throughout this essay, in which case 'waar-in- $M_{n}$ ' would denote the privileged semantic notion). Regardless of the theory we are considering, there will be one crucial semantic notion, one relevant to the truth evaluability of that theory, that must be distinguished from all other notions we may wish to define. When interpreting evolutionary theory, for example, we must offer an interpretation of the models of the theory and pinpoint the specific property that is constitutive of truth for evolutionary theory. That property is the correct one for defining truth in evolutionary theory, just as truth-in- $M_{n}$ is the correct one for defining truth in the Life theory. The deflationist has no explanation for why those notions, rather than any other one, are the correct notions for understanding truth and cannot say what it is that those notions have in common that separates them from their contenders. For deflationists, truth is merely a device for disquotation or denominalization; it is not to be understood as a privileged semantic notion, as the constructive empiricist must take it to be. That constructive empiricists must privilege some semantic notions above others is evidence that they cannot rely on a metaphysically austere conception of truth.

Finally, consider the deflationist's claim that the various kinds of truthin-a-model function as disquotational devices and thus are acceptable on 
deflationary grounds. Granted, truth-in- $M_{n}$ appears to be disquotational in $\mathbf{T}_{\mathbf{2}}$ (as does truth-in- $E_{n}$ in $\mathbf{E} \mathbf{A}_{2}$ ), which includes biconditionals like

'Snow is white' is true-in- $M_{n}$ if and only if snow is white.

Such biconditionals resemble classic "T-sentences" like

'Snow is white' is true if and only if snow is white.

For deflationists, T-sentences typically are necessarily true, for their left and right conditions are cognitively equivalent. However, the biconditionals forming $\mathbf{T}_{2}$ are importantly different. Consider again the Life sentence ' $A$ is ON at $t_{0}$ ', and suppose that the world is as $M_{512}$ depicts it (with all cells initially ON, as shown in the figure at the start of Section 4). Now, ex hypothesi, our Life theory $L$ is true because one of its models (namely, $M_{512}$ ) is isomorphic to the actual world. Let us then instantiate $\mathbf{T}_{\mathbf{2}}$ with $L$ and $M_{512}$. Doing so generates the biconditional

' $A$ is ON at $t_{0}$ ' is true-in- $M_{512}$ if and only if $A$ is ON at $t_{0}$.

It seems, then, that we have defined truth in terms of truth-in- $M_{512}$ and have then employed truth-in- $M_{512}$ merely as a device for disquotation. There appears to be nothing here that is unsavory to the deflationist. However, appearances here are deceiving. The biconditional I have isolated, while true, is only contingently true. Its left condition is essentially a mathematical truth; regardless of whether the actual world is accurately described by $M_{1}, M_{2}$, or some other $M_{n}$, the sentence ' $A$ is oN at $t_{0}$ ' is true-in- $M_{512}$ ' is true, and necessarily so. However, the right-hand condition expresses a contingent matter of fact. In some worlds $A$ is OFF at $t_{0}$, and in some worlds it is ON at $t_{0}$. Hence the biconditionals constituting $\mathbf{T}_{2}$ are only contingently true. That the biconditionals forming $\mathbf{T}_{2}$ are contingent is important because such a conclusion is at odds with the traditional deflationist understanding of T-sentences. Deflationists typically take Tsentences to be necessarily true (Horwich 1990 and Field 1994 are prime examples). Since truth, on their view, is a deflated notion, predicating it of something adds no substance to it. As a result, T-sentences are necessarily true, for their left-hand conditions bear no cognitive content not already possessed by their right-hand conditions. For deflationists, Tsentences are vacuous. As a result, deflationists and substantivists disagree on the modal status of T-sentences: substantivists typically argue that Tsentences, while true, are contingent. Whether certain T-sentences are true depends on contingent matters of fact including, among others, facts involving the meanings of certain words. Deflationists should thus hesitate to embrace a view that requires T-sentences to be metaphysically contingent.

Further, we must recognize that when deflationists claim that truth-in$M_{512}$ is operating only as a device for disquotation, they are ignoring the 
element of interpretation that makes the T-sentences that feature it true. Indeed, assuming the world to be as $M_{512}$ describes it, the biconditional

' $A$ is ON at $t_{0}$ ' is true-in- $M_{512}$ if and only if $A$ is ON at $t_{0}$

is true. It is misleading, however, to think of that biconditional as being partially constitutive of the deflationist constructive empiricist's definition of truth. The kind of biconditional that is really constitutive of truth for the deflationist constructive empiricist is far more complicated and not at all disquotational:

' $A$ is ON at $t_{0}$ ' is true-in- $M_{512}$ if and only if $M_{512}\left(i_{1}(A), i_{3}\left(t_{0}\right)\right)=$ $i_{2}(\mathrm{ON})$.

That kind of biconditional satisfies the condition of being necessarily true (for each of its conditions are mathematical truths), but it clearly shows that truth-in- $M_{512}$ is not a device for disquotation. As we saw above, the biconditionals forming $\mathbf{T}_{2}$ are only contingently true, and thus the inference from ' $A$ is ON at $t_{0}$ ' is true-in- $M_{512}$ ' to ' $A$ is ON at $t_{0}$ ' is not logically secure. If truth-in- $M_{512}$ were a genuine device for disquotation, that inference would be trivial. The biconditionals that are constitutive of truthin- $M_{512}$ are formed from conditions that clearly are not cognitively equivalent; the left-hand side involves sentences from normal English, and the right-hand side involves only complicated mathematical symbolizations. Consequently, we arrive at the appearance of a disquotable sentence only through a detour involving a complicated translation between ordinary English and the mathematical language of the Life theory's interpretation. What we have in the notion of truth-in-a-Life model is not something that resembles straightforward disquotation. On a typical deflationist program, truth is immediately disquotable: no translation or further premise is required to fuel the inference between 'Snow is white' is true' and 'Snow is white'. For the notion of truth-in-a-model, no such immediate disquotation is possible, since the theoretical interpretation is playing a necessary, mediating role. Truth-in-a-model, regardless of the version being considered, cannot function as a simple device for disquotation, as the deflationist would have it.

To summarize, the deflationist constructive empiricist characterizes the aim of science as pursuing empirical adequacy, which is defined in terms of truth. Since the deflationist must show that his appeal to truth is acceptable on deflationary grounds, he must show that his reliance on truth does not go beyond its disquotational or denominalizing features. Further, as a constructive empiricist, he must understand theories as sets of models paired with an interpretation. The attempts at offering a deflationary analysis of the truth and empirical adequacy of scientific theories end up relying on further semantic notions, which is already a strike 
against the deflationist (for deflationist reductions tend to include no further semantic notions, as in the breakdown of 'Something Kant said is true'). Further, those additional semantic notions - in most cases notions that are likely never to be defined explicitly_raise the question of why they are crucial to the notion of theory truth and theory empirical adequacy rather than other semantic notions, a question that deflationists are at pains to answer. As a result, the deflationist lacks a rationale for saying what it is that the various semantic notions he must employ all share such that they are the relevant notions for evaluating a theory's empirical adequacy and truth. Finally, deflationists are faced with the severe problem that the notion of truth-in-a-model on which they rely does not serve as a disquotational device at all, contrary to what might appear to be the case: $\mathbf{T}_{\mathbf{2}}$ and $\mathbf{E} \mathbf{A}_{\mathbf{2}}$ are simply not disquotational accounts of truth and empirical adequacy. In short, without relying on the resources of a substantive account of truth, the deflationist suffers the inability of offering accounts of truth and empirical adequacy that are required to make sense of constructive empiricism.

6. Conclusion. If my diagnosis is correct, constructive empiricists require a more substantive account of truth than can be offered by deflationists. Deflationists, recall, subscribe to the thesis of conceptual deflationism, the claim that truth is not richly connected with other philosophical concepts - that its conceptual contributions are limited to its disquotational and denominalizing functions. My aim has been to show that mere deflationary truth does not suffice for the constructive empiricist's account of key notions in the philosophy of science: the truth and empirical adequacy of scientific theories, scientific realism, and even constructive empiricism itself.

What conclusion is to be drawn? Should constructive empiricism be rejected as an untenable philosophy of science, given the many merits of deflationism? Should constructive empiricism be rejected as unmotivatedor even incoherent - since one of its major motivations (metaphysical asepticism) is undermined by its commitment to a robust theory of truth? ${ }^{17}$ Perhaps constructive empiricism's very construal of the nature of realism and empiricism should be rejected, thus paving the way for novel ways of articulating the realism debate in the philosophy of science. ${ }^{18}$ Or, alternatively, should deflationism about truth be rejected, given its failure

17. Ladyman, in an argument not dissimilar to my own, takes that option after arguing that constructive empiricists are committed to a substantive account of modality (2000). See Monton and van Fraassen 2003, Ladyman 2004, and Muller 2005 for further discussion.

18. I take Crispin Wright (1992) to adopt that option. 
to adequately account for what the constructive empiricist claims to be the aim of science? I have not argued in defense of one of those conclusions rather than the others; I merely have tried to identify an inconsistency between two philosophical views that otherwise would seem to form a natural pair. Constructive empiricists and deflationists both share the desire to offer their theories with as little recourse to metaphysics as is necessary. My own suspicion is that the constructive empiricist's analysis of the dispute between empiricists and realists has much to recommend it; traditionally, truth has played a prominent role in discussions of realism (see Sayre-McCord 1986), and I see no conclusive reason to dispute that centrality. Van Fraassen's characterization of realism and empiricism is natural and convincing: the realist argues that the aim of science is to discover the truth about the world, while the empiricist argues that science aims to achieve empirical adequacy, to discover the truth about the phenomenal world. If truth and realism are indeed inextricably linked, then we have reason to be suspicious of conceptual deflationism - we appear to have an area of ripe philosophical inquiry where truth seems to be put to use beyond its role as a device for disquotation and denominalization. Hence, I am inclined to think that truth is not merely a tool for disquoting and denominalizing. Deflationists were correct to identify those functions of the truth predicate, but there is more to truth than its basic linguistic functions. Truth is a rich concept, essential to our understanding of the aim of science.

What, to conclude, of constructive empiricism's call for metaphysical austerity? Does my contention that it requires a substantive account of truth undermine the spirit of empiricism that drives and motivates van Fraassen's preferred philosophy of science? One response available to the constructive empiricist, though not a particularly interesting one, is that he never claimed to offer a philosophy of science with no metaphysical commitments, just one with as little metaphysics as possible. As it turns out, it is just not possible to make do without a substantive theory of truth. However, there are more fruitful responses. For instance, the constructive empiricist can distinguish between the metaphysical commitments one undertakes in accepting a scientific theory and the metaphysical commitments one undertakes in accepting a philosophical position like constructive empiricism. My arguments for why constructive empiricists cannot be deflationists only relate to the latter kind of commitment. The constructive empiricist can agree with my conclusions and maintain that I have not shown that what it is to accept a scientific theory is any more metaphysically committing than he originally stated. It is only the one who embraces the philosophical position of constructive empiricism who is burdened with a more substantive account of truth. The original, austere conception of what is involved in accepting a scientific theory is unchanged. 
Another possible response points toward future research. I have not argued for exactly what kind of truth the constructive empiricist requires; rather, I have argued only that a deflationary account is insufficient. The constructive empiricist needs an account that is more robust than that offered by the deflationist, but it does not follow from my conclusion that a constructive empiricist requires, say, a classical correspondence theory of truth. Objections to correspondence theories are well known, and constructive empiricists might do well to share along with deflationists (and van Fraassen himself now) the worries that motivated deflationism in the first place. Still, there may be another option. Perhaps there is a theory of truth that, while more substantive than a bare deflationary account, nevertheless avoids the excesses of traditional correspondence theories. Such a theory would be acceptable to the empiricist and could figure into his account of the nature of scientific inquiry. The sort of conceptual primitivism envisaged by Frege and Davidson may be such a view. The primitivist can allow that there are deep conceptual connections between truth and other philosophically important notions. Yet the primitivist is not necessarily committed to the sorts of metaphysical posits that accompany correspondence theories. After all, rejecting conceptual deflationism is not tantamount to rejecting metaphysical deflationism. Primitivism might offer just the sort of middle ground that the constructive empiricist needs.

\section{REFERENCES}

Bar-On, Dorit, and Keith Simmons (2007), "The Use of Force against Deflationism: Assertion and Truth", in Dirk Greimann and Geo Siegwart (eds.), Truth and Speech Acts: Studies in the Philosophy of Language. London: Routledge, 61-89.

Bub, Jeffrey, and David MacCallum (1988), review of Images of Science: Essays on Realism and Empiricism, with a Reply from Bas C. van Fraassen by Paul M. Churchland and Clifford A. Hooker, Foundations of Physics Letters 1: 395-399.

David, Marian (1994), Correspondence and Disquotation: An Essay on the Nature of Truth. New York: Oxford University Press.

Davidson, Donald (1996), “The Folly of Trying to Define Truth”, Journal of Philosophy 93: 263-278.

Ellis, Brian (1985), "What Science Aims to Do", in Paul M. Churchland and Clifford A. Hooker (eds.), Images of Science: Essays on Realism and Empiricism, with a Reply from Bas C. van Fraassen. Chicago: University of Chicago Press, 48-74.

Field, Hartry (1994), "Deflationist Views of Meaning and Content", Mind 103: 249-285.

Fine, Arthur (1984), "And Not Anti-realism Either", Noûs 18: 51-65.

(1986), "Unnatural Attitudes: Realist and Instrumentalist Attachments to Science", Mind 95: 149-179.

Frege, Gottlob ([1918-19] 1956), "The Thought: A Logical Inquiry", Mind 65: 289-311. Reprint. Translated by A. M. and Marcelle Quinton. Originally published in Beiträge zur Philosophie des Deutschen Idealismus.

Gardner, Martin (1970), "The Fantastic Combinations of John Conway's New Solitaire Game 'Life", Scientific American 223: 120-123.

Hill, Christopher (2002), Thought and World: An Austere Portrayal of Truth, Reference, and Semantic Correspondence. Cambridge: Cambridge University Press. 
Horwich, Paul (1990), Truth. Oxford: Blackwell.

Jennings, Richard (1989), "Scientific Quasi-Realism", Mind 98: 225-245.

Kitcher, Philip (2001), "Real Realism: The Galilean Strategy", Philosophical Review 110: $151-197$.

Künne, Wolfgang (2003), Conceptions of Truth. Oxford: Clarendon.

Ladyman, James (2000), "What's Really Wrong with Constructive Empiricism? Van Fraassen and the Metaphysics of Modality", British Journal for the Philosophy of Science 51: $837-856$.

(2004), "Constructive Empiricism and Modal Metaphysics: A Reply to Monton and van Fraassen", British Journal for the Philosophy of Science 55: 755-765.

Monton, Bradley, and Bas C. van Fraassen (2003), "Constructive Empiricism and Modal Nominalism", British Journal for the Philosophy of Science 54: 405-422.

Muller, F. A. (2005), "The Deep Black Sea: Observability and Modality Afloat", British Journal for the Philosophy of Science 56: 61-99.

Psillos, Stathis (1999), Scientific Realism: How Science Tracks Truth. London: Routledge.

Putnam, Hilary (1975), Mathematics, Matter, and Method: Philosophical Papers, vol. 1. Cambridge: Cambridge University Press.

Quine, W. V. (1970), Philosophy of Logic. Englewood Cliffs, NJ: Prentice-Hall.

Rosenhagen, Raja (2006), "Indexical Truth and Anti-metaphysical Inclinations: Getting Rid of the Remnants of Realism", in Andreas Berg-Hildebrand and Christian Suhm (eds.), Bas C. van Fraassen: The Fortunes of Empiricism. Frankfurt: Ontos, 81-91.

Sayre-McCord, Geoffrey (1986), "The Many Moral Realisms", Southern Journal of Philosophy 24 (suppl.): 1-22.

Sellars, Wilfrid (1963), Science, Perception and Reality. New York: Humanities Press.

Suppe, Frederick (1989), The Semantic Conception of Theories and Scientific Realism. Urbana: University of Illinois Press.

Teller, Paul (2001), “Whither Constructive Empiricism?", Philosophical Studies 106: 123 150.

Thompson, Paul (1989), The Structure of Biological Theories. New York: SUNY Press.

van Fraassen, Bas C. (1970), "On the Extension of Beth's Semantics of Physical Theories", Philosophy of Science 37: 325-339.

- (1972), "A Formal Approach to the Philosophy of Science", in Robert G. Colodny (ed.), Paradigms and Paradoxes: The Philosophical Challenge of the Quantum Domain. Pittsburgh: University of Pittsburgh Press, 303-366.

(1980), The Scientific Image. Oxford: Clarendon.

(1987), "The Semantic Approach to Scientific Theories", in Nancy J. Nersessian (ed.), The Process of Science. Dordrecht: Nijhoff, 105-124.

- (1989), Laws and Symmetry. Oxford: Clarendon.

(1991), Quantum Mechanics: An Empiricist View. Oxford: Clarendon.

- (1997), "Elgin on Lewis's Putnam's Paradox", Journal of Philosophy 94: 85-93.

- (2006), "Replies to the Papers", in Andreas Berg-Hildebrand and Christian Suhm (eds.), Bas C. van Fraassen: The Fortunes of Empiricism. Frankfurt: Ontos, 125-171. (2008), Scientific Representation: Paradoxes of Perspective. Oxford: Clarendon.

Williams, Michael (1999), "Meaning and Deflationary Truth", Journal of Philosophy 96: 545-564.

Wright, Crispin (1992), Truth and Objectivity. Cambridge, MA: Harvard University Press. 